\title{
Analysis of the performance of the photovoltaic array through the exergy efficiency
}

\author{
M. Calderón ${ }^{1}$, A.J. Calderón ${ }^{1}$, A. Ramiro ${ }^{2}$, J.F. González ${ }^{2}$ and I. González ${ }^{1}$ \\ ${ }^{1}$ Department of Electrical Engineering. ${ }^{2}$ Department of Applied Physics. \\ E.I.I., Extremadura University
}

\author{
Avenida de Elvas s/n, 06071 Badajoz (Spain) \\ Phone/Fax number: +34 924 289618/01, e-mail: aramiro@unex.es
}

\begin{abstract}
This work is part of an exergy analysis conducted during the operation of a test-bed hybrid wind/solar generator with hydrogen support, designed and constructed at the Industrial Engineering School of the University of Extremadura, Badajoz (Spain). An exergy balance analysis has been made of the different components of the system, calculating their exergy efficiencies and exergy losses, and proposing future improvements to increase the efficiency of the use of the surplus energy produced by the wind/solar generator. Here we only present the results corresponding to the photovoltaic generator's exergy analysis.
\end{abstract}

\section{Key words}

Wind-solar hydrogen system, photovoltaic array, exergy of the solar radiation, exergy efficiency.

\section{Introduction}

The integration into the energy mix of renewable resources such as solar and wind power is becoming increasingly attractive. They are already widely used as substitutes for fossil-fuel produced energy, and will help to minimize atmospheric degradation. The major advantage of their combined use in a hybrid system is that the reliability of the system is enhanced [1]. Nevertheless, renewable energy (RE) sources such as solar and wind clearly have to be included in the design with recognition of their intermittent nature, and power supply systems based on them will be subject to strong short-term and seasonal variations in their energy output. There is therefore a need for storage systems that can accumulate the energy produced in periods of low demand to utilize it when the demand is high, ensuring full utilization of the intermittent sources that are available. Hydrogen can be used as a storage medium for intermittent and seasonal renewable technologies, endowing the overall system with greater reliability that would make it better suited to remote stand-alone applications [2].

A test-bed stand-alone RE system based on hydrogen energy storage has been developed and installed in the Technical Thermodynamics Laboratory of the Industrial Engineering School of the University of Extremadura, in Badajoz (Spain). It has been successfully tested for autonomous operation with a control system and power conditioning devices. It comprises a photovoltaic generator, a wind-turbine generator, a battery set, an electrolyzer, a metal-hydride system for hydrogen storage, a fuel cell, and a supervisory control and data acquisition system. In this system, excess energy produced with respect to the load requirement is sent to the electrolyzer for hydrogen production. When the load requirement exceeds the energy produced by the RE sources, the stored hydrogen is fed to a fuel cell to produce electricity. Experimental results clearly indicate that such a stand-alone RE system based on hydrogen production is safe and reliable $[3,4]$.

The experimental installation's geographical data are given in Table 1.

Table 1. Location of the installation.

\begin{tabular}{|c|c|c|}
\hline Latitude & Longitude & Altitude \\
\hline $38^{\circ} 53^{\prime} 1.80^{\prime \prime} \mathrm{N}$ & $6^{\circ} 58^{\prime} 12.94^{\prime \prime} \mathrm{W}$ & $169 \mathrm{~m}$ \\
\hline
\end{tabular}

Table 2 presents the components and operational characteristics of the wind-solar installation with hydrogen support. The electrolyzer and the fuel cell are of the PEM (Proton Exchange Membrane) type. The hydrogen produced by the electrolyzer is fed directly to a metal hydride bottle. This storage canister is filled with a special metal hydride alloy.

Table 2. Principal devices of the wind-solar installation with hydrogen support.

\begin{tabular}{|l|l|}
\hline \multicolumn{1}{|c|}{ Component } & \multicolumn{1}{|c|}{ Characteristics } \\
\hline $\begin{array}{l}\text { Photovoltaic } \\
\text { generator }\end{array}$ & $\begin{array}{l}\text { Monocrystalline silicon solar module } \\
\text { Helios H-45 (45 Wp, 12 V) }\end{array}$ \\
\hline Wind generator & $\begin{array}{l}\text { Rutland-913 Windcharger (90 W at wind } \\
\text { speed of 10 m/s) }\end{array}$ \\
\hline Electrolyzer & $\begin{array}{l}\text { Type PEM. 10 cells. Hydrogen Works. } \\
\text { Hart-250. Maximum pressure: 6 bar. } \\
\text { Working temperature: 15-45 }{ }^{\circ} \mathrm{C}\end{array}$ \\
\hline Fuel cell & $\begin{array}{l}\text { Type PEM. 10 cells. Heliocentrics, 40 W } \\
\text { rated power. Working temperature:5-50 } \\
{ }^{\circ} \mathrm{C}\end{array}$ \\
\hline $\begin{array}{l}\text { Metal hydride } \\
\text { bottle }\end{array}$ & $\begin{array}{l}\text { Ovonic. Hydrogen capacity: 600 LN (10 } \\
\text { bar). }\end{array}$ \\
\hline Battery & Trojan. 85 Ah. 12 V \\
\hline Electronic load & HP 6063B. 240 W max. \\
\hline $\begin{array}{l}\text { Programmable } \\
\text { logic controller }\end{array}$ & Siemens S7 313 C-2 DP \\
\hline Touch panel & Siemens. Simatic touch panel TP277 6". \\
\hline
\end{tabular}


The working principle of the hybrid system is shown in the scheme of Fig. 1.

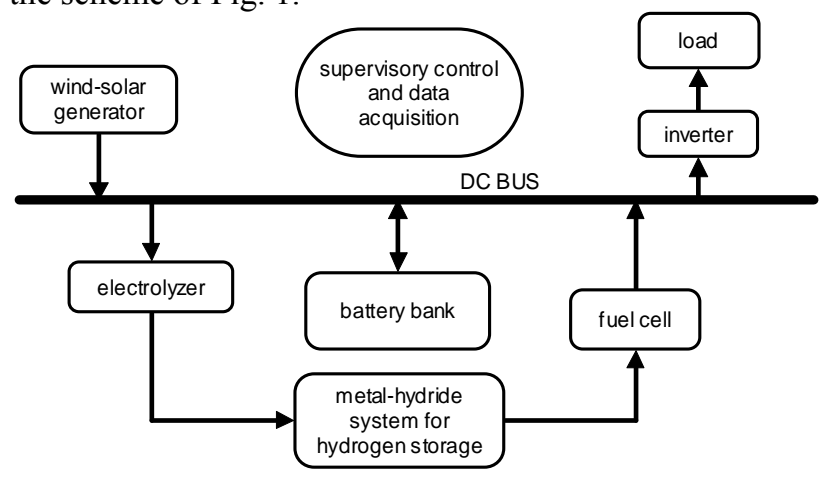

Fig. 1 - Scheme of the wind-solar hydrogen system.

The wind-solar generator is installed on the flat roof of the Industrial Engineering School. It consists of a Rutland-913 wind-turbine generator of $90 \mathrm{~W}$ at a wind speed of $10 \mathrm{~m} / \mathrm{s}$, and two Helios H-45 photovoltaic modules of $45 \mathrm{Wp}$. Next to this tower there is an anemometer to monitor the wind speed. The photovoltaic modules are installed on a south-facing metallic structure of variable tilt. On this structure there is also a pyranometer which measures the irradiance incident on the plane of the photovoltaic modules. The rest of the elements are mounted on an experimental bench constructed on a perforated metal sheet (Fig. 2).

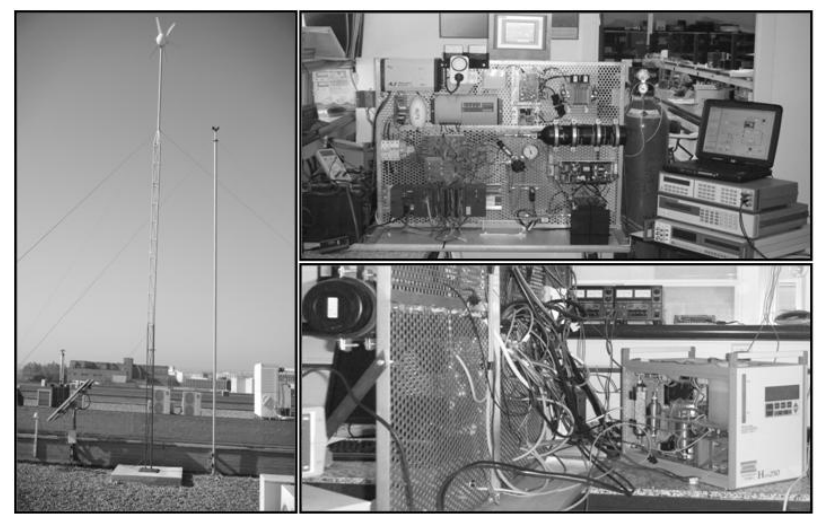

Fig. 2 - Wind-solar generator, experimental bench, and electrolyzer.

\section{Exergy analysis}

Exergy analysis is a technique that uses the conservation of mass and conservation of energy principles together with the second law of thermodynamics for the analysis, design, and improvement of energy systems and other analogous systems [5].

Exergy is defined as the maximum amount of work that can be done by a system or a flow of matter or energy as it comes to equilibrium with a reference environment. It is a measure of the potential of the system or flow to cause change as a consequence of not being completely in stable equilibrium relative to the reference environment. Unlike energy, exergy is not subject to a conservation law (except for ideal, or reversible, processes). Rather, exergy is consumed or destroyed, due to the irreversibilities present in every real process. The exergy consumption during a process is proportional to the entropy created due to irreversibilities associated with that process.

Exergy analysis is useful for improving the efficiency of energy resource use, since it quantifies the locations, types, and magnitudes of waste and losses. In general, exergy analysis provides more meaningful efficiencies than does energy analysis, since exergy efficiencies are always a measure of how closely the efficiency of a process approaches the ideal. Therefore, exergy analysis identifies accurately the margin available to design more efficient energy systems by reducing inefficiencies. Many engineers and scientists suggest that thermodynamic performance is best evaluated using exergy analysis because it provides greater insight and is more useful in deciding on efficiency improvement efforts than energy analysis.

In an exergy analysis, the characteristics of a reference environment need to be specified - usually its temperature, pressure, and chemical composition. The results of exergy analyses are then relative to that reference environment, which in most applications is modeled after the actual local environment. The exergy of a system is zero when it is in equilibrium with the reference environment - a situation known as the dead state in which the system is in mechanical (pressure), thermal (temperature), and chemical (chemical potential) equilibrium with its surroundings. In addition, the system has no motion or elevation relative to the environment. Under these conditions, there is no possibility of either any spontaneous change within the system or the environment, or of any interaction between them. The exergy is zero [6].

To evaluate the quality of a power system using exergy analysis, one defines its exergy efficiency by the following expression:

$$
\eta_{\mathrm{ex}}=\frac{\mathbf{w}_{\mathbf{u}}}{\mathbf{w}_{\mathrm{u}_{\text {max }}}}=\frac{\mathbf{P}_{\mathbf{u}}}{\mathbf{P}_{\mathbf{u}_{\text {max }}}}
$$

where $\mathrm{Wu}$ and $\mathrm{Pu}$ are the useful work and power obtained from the system, respectively, and $\mathbf{W}_{\mathbf{u}_{\max }}$ and $\mathbf{P}_{\mathbf{u}_{\text {max }}}$ are the maximum work and maximum power that can be obtained from the system in a reversible process. These maximum values are given by the decrease in exergy of the system over the course of the process. That is, for any given process:

$$
\begin{gathered}
\mathbf{W}_{\mathbf{u}_{\text {max }}}=\mathbf{E x _ { 1 }}-\mathbf{E x _ { 2 }} \\
P_{\mathbf{u}_{\max }}=\mathbf{E} \dot{x}_{1}-\dot{E} \dot{x}_{2}
\end{gathered}
$$

with $\mathrm{Ex}_{1}$ and $\mathrm{Ex}_{2}$ being the input and output exergies of the system, and $\mathbf{E x}_{\mathbf{1}}$ and $\mathbf{E x}_{\mathbf{2}}$ the same quantities expressed per unit time. The above expressions give the exergy loss, Ex $_{\text {loss }}$, occurring in a given process as a result of the irreversibilities: 


$$
\mathbf{E x}_{\text {loss }}=\mathbf{W}_{\mathbf{u}_{\text {max }}}-\mathbf{W}_{\mathbf{u}}=\mathbf{E x}_{\mathbf{1}}-\mathbf{E x}_{\mathbf{2}}-\mathbf{W}_{\mathbf{u}}
$$

or, per unit time:

$$
\dot{\mathbf{E x}_{\text {loss }}}=\mathbf{P}_{\mathbf{u}_{\text {max }}}-\mathbf{P}_{\mathbf{u}}=\dot{\mathbf{E x}_{\mathbf{1}}}-\dot{\mathbf{E x}_{\mathbf{2}}}-\mathbf{P}_{\mathbf{u}}
$$

One can then express the exergy efficiency in terms of exergy loss:

$$
\eta_{\mathrm{ex}}=1-\frac{\dot{E} x_{\text {loss }}}{\dot{E x}_{1}-\dot{E x_{2}}}
$$

Unlike the energy efficiency which only gives quantitative information about the system, the exergy efficiency also carries information about quality since, as one deduces from the above expressions, the closer its value is to unity, the more reversible is the process.

\section{Exergy efficiency of the photovoltaic array}

Solar photovoltaic (PV) technology converts sunlight directly into electrical energy. Direct current electricity is produced, which can be used in that form, converted to alternating current, or stored for later use. A PV cell is a type of photochemical energy conversion device. Alternatives include devices based on the photoelectric effect and on biological photosynthesis. Such systems operate by collecting a fraction of the radiation within some range of wavelengths. In PV devices, photon energies above the cutoff (or band-gap) energy are dissipated as heat, while photons with wavelengths longer than the cutoff wavelength are not used.

The energy conversion factor of a solar PV system is sometimes described as the efficiency, but this usage can lead to confusion. The efficiency of a solar PV cell can be considered as the ratio of the electricity generated to the total, or global, solar irradiation. In this definition only the electricity generated by a solar PV cell is considered. Other parameters of PV systems which may affect efficiency, such as ambient temperature, cell temperature, and chemical components of the solar cell, are not directly taken into account [7].

Applying the definition of exergy efficiency to the photovoltaic system, one obtains the following expression:

$$
\eta_{\text {ex }}=\frac{P}{\text { Ex }_{\text {solar }}}
$$

where $\mathrm{P}$ is the electrical power generated by the photovoltaic modules, which is a totally utilizable energy, and $\mathbf{E x}_{\text {solar }}$ is the exergy of the solar radiation incident on them per unit time. Strictly speaking, the photovoltaic modules heat up as a result of their exposure to sunlight, and also emit a quantity of heat into the surroundings which, as it comes from a heat source not in equilibrium with the surroundings, has a certain exergy. The value of the heat emitted is given by the expression:

$$
\dot{\mathbf{Q}}=\mathbf{U A}\left(\mathbf{T}_{\mathbf{m}}-\mathbf{T}_{\mathbf{0}}\right)
$$

where $\mathrm{U}$ is the overall heat transfer coefficient from the module to the surroundings, $\mathrm{A}$ is the heat exchange area, and $\mathrm{T}_{\mathrm{m}}$ and $\mathrm{T}_{0}$ are the module and ambient temperatures, respectively. The exergy of this heat - its maximum capacity to produce useful work - is:

$$
\operatorname{Ex}\left(Q, T_{m}, T_{0}\right)=Q\left(1-\frac{T_{0}}{T_{m}}\right)
$$

The mean difference between the module and the ambient temperatures during the hours of sun, measured during May, was less than $10^{\circ} \mathrm{C}$. This allows us, using Eqs. (7) and (8), to consider the exergy of the heat emitted by the modules to be negligible relative to the electrical power they supply. Therefore, to calculate the exergy efficiency of the photovoltaic modules, we considered only the electrical power and the radiation exergy.

The power $\mathrm{P}$ generated by the modules can be calculated as the product of their output current (I) and the voltage (V) across their terminals. The exergy of the solar radiation $\left(\dot{\mathbf{E}} \mathbf{x}_{\text {solar }}\right)$ has been studied by many researchers [8-14]. The different equations they propose give similar results [14]. Here we shall use the proposal given by Petel in 1964 [15]:

$$
\dot{\mathrm{Ex}}_{\text {solar }}=\mathrm{AG}\left[1-\frac{4}{3}\left(\frac{\mathrm{T}_{0}}{\mathrm{~T}_{\mathrm{s}}}\right)+\frac{1}{3}\left(\frac{\mathrm{T}_{0}}{\mathrm{~T}_{\mathrm{S}}}\right)^{4}\right]
$$

where A is the area of the photovoltaic modules $\left(0.07 \mathrm{~m}^{2}\right.$, in our case), $G$ is the global incident irradiance, $T_{0}$ is the ambient temperature, and $\mathrm{T}_{\mathrm{s}}$ is the temperature of the Sun $(5780 \mathrm{~K})$.

To calculate the above parameters, we sampled the following variables at one minute intervals: voltage and current supplied by the photovoltaic modules, ambient temperature (with a THIES-CLIMA 2.1265.10 model temperature sensor), and global irradiance on the plane of the modules (with a Kipp \& Zonen CMP-11 pyranometer).

Figure 3 shows the value of the overall irradiance incident on the inclined plane of the photovoltaic modules, and the solar exergy for a cloudless day -20 May 2010.

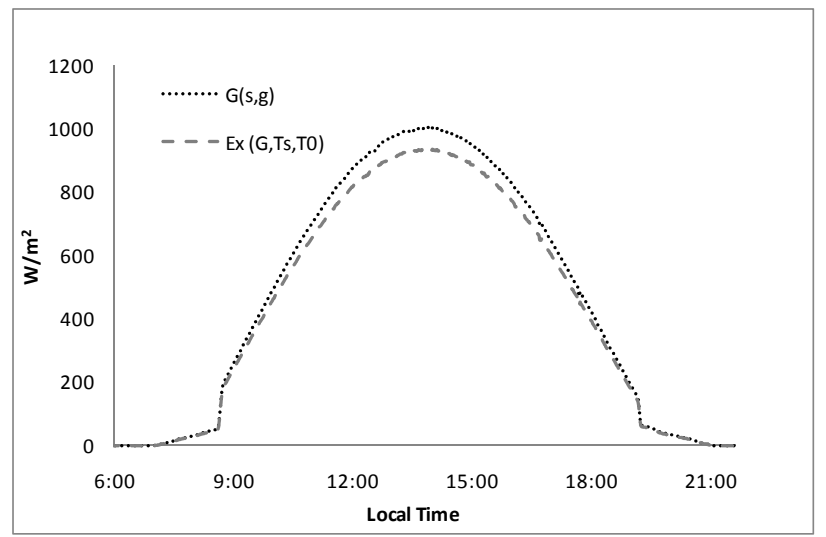

Fig. 3. Global irradiance and solar exergy, 20 May 2010. 
One observes in the figure that, as was to be expected according to Eq. (9), the shape of the exergy curve follows that of the irradiance, and the greater the value of the irradiance, the greater the difference between the two. The figure also illustrates solar radiation's great capacity for useful work (exergy) due to the high temperature of the Sun. Specifically, for the day in question, the values of the overall solar radiation on the inclined plane and of the exergy of the irradiation on that plane were 7.36 $\mathrm{kWh} / \mathrm{m}^{2}$ and $6.86 \mathrm{kWh} / \mathrm{m}^{2}$, corresponding to a useful working capacity of $93.11 \%$.

Figure 4 shows the exergy of the radiation incident on the inclined plane, i.e., the maximum electrical power obtainable from the radiation, and the power supplied by the photovoltaic modules, also for 20 May 2010. Clearly, the actual power extracted from the photovoltaic modules over the course of the day is much less than could be extracted, meaning that there is a major loss of exergy as a result of the irreversibilities of the process. This behaviour of the photovoltaic conversion is reflected in the process's low exergy efficiency which, as is shown in Fig. 5, stays at around 9.5\% throughout the day, far from the $100 \%$ that would correspond to the ideal, or reversible, process.

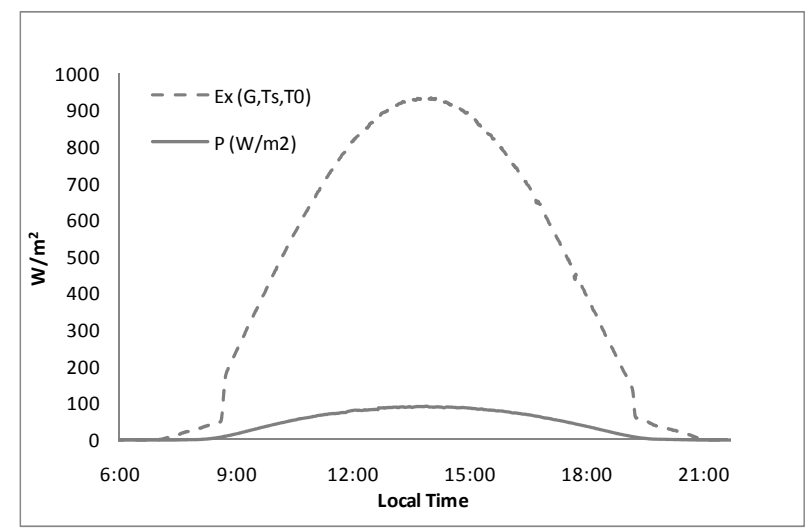

Fig. 4. Solar exergy and power of photovoltaic modules, 20 May 2010.

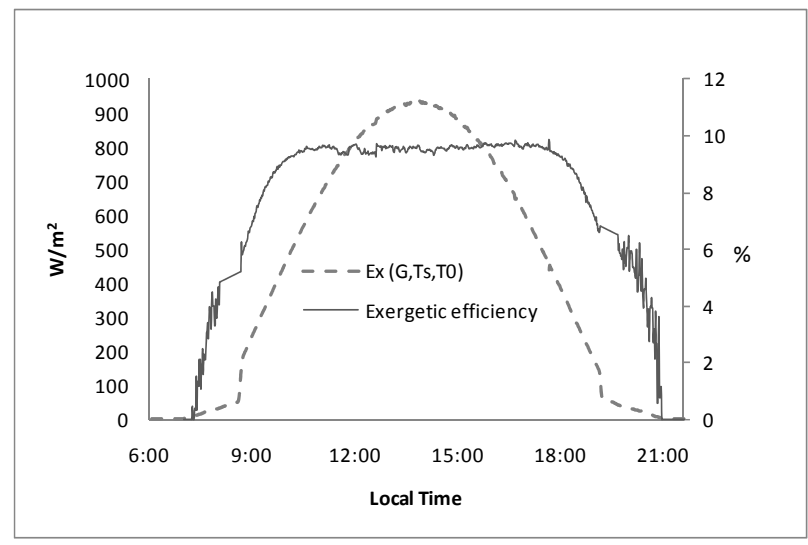

Fig. 5. Solar exergy and exergetic efficiency of photovoltaic modules, 20 May 2010.

Finally, Fig. 6 shows the mean daily exergy efficiency of the photovoltaic system during May, together with the exergy incident on the modules on each day. The figure shows the influence of the battery charge controller on the efficiency of the photovoltaic modules. On sunny days, when there is a high radiation exergy, the battery quickly reaches its maximum charge, and the controller switches to floating charge mode and cuts the current flow to the battery. The result is a reduced supply of power to the system which, together with the higher value of the radiation exergy, leads to a notable decline in the modules' exergy efficiency, in accordance with Eq. (6). The opposite is the case on partly cloudy days on which, as the battery's charge falls, the controller allows current to pass, increasing the power supplied by the modules which, together with the lower value of the radiation exergy, leads to high values of the exergy efficiency. The present results are somewhat lower than those reported by other workers [9], and underline the need to modify the way power is supplied from the photovoltaic modules to the system through the controller, since this is a source of a significant waste of the solar exergy incident on the modules.

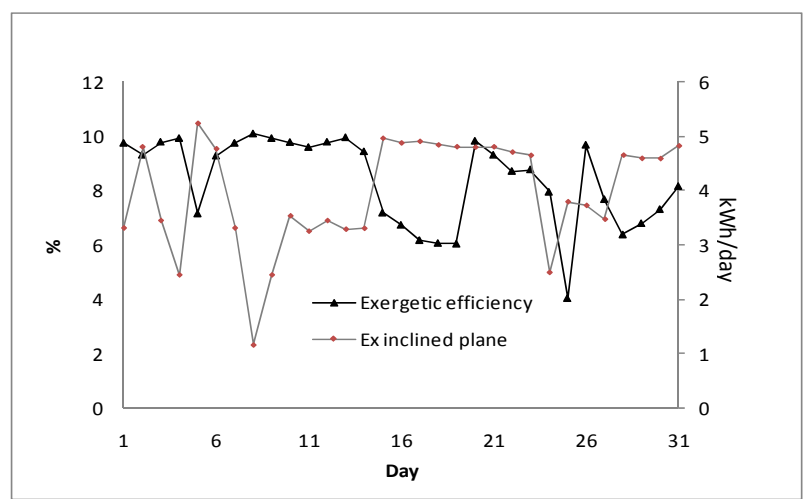

Fig. 6. Exergetic efficiency photovoltaic modules and exergy incident on the inclined plane, May 2010.

As a final conclusion of this section, we can state that photovoltaic conversion with silicon modules, despite their advantages and current widespread use, implies an enormous loss of exergy. These exergy losses are reflected in Fig. 7 which shows them as absolute values and as percentages. One observes that the relative losses exceed $90 \%$ throughout the day. Thus, huge amounts of usable energy, of useful work, are being lost, which some other type of direct converter might be able to take advantage of.

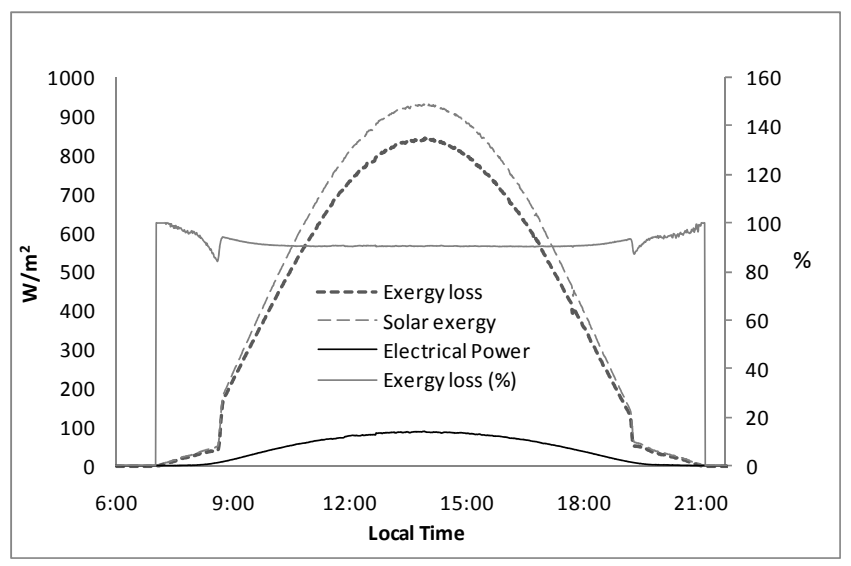

Fig. 7. Exergy loss on photovoltaic modules 


\section{Conclusions and future work}

In this study, we have described an exergy analysis of the energy behaviour of the photovoltaic array of a test-bed hybrid photovoltaic-wind system with hydrogen storage, installed in the School of Industrial Engineering at the University of Extremadura. We determined the exergy efficiency of the photovoltaic array of the system, and calculated the exergy losses that occur in them as a result of irreversibilities.

The results showed the photovoltaic modules have a low exergy efficiency $\left(\eta_{\mathrm{ex}}=8.39 \%\right)$. With respect to the photovoltaic system, the exergy analysis showed that today's silicon modules take very little advantage of the high exergy content of solar radiation. In our specific case, the system's poor exergy efficiency is also related to the mode of operation of the electrolyzer. This functions at a fixed operating point, i.e., it consumes a constant current, which is provided by the photovoltaic generator. As the production capacity of the modules rises, the electrolyzer's operating point remains unchanged, so that there is no increase in its output despite the existence of a surplus of energy, which is therefore wasted. To use the available energy, the electrolyzer would have to have a variable operating point. Then, with increasing incident solar exergy, the current and power consumed by the electrolyzer would also increase, improving the system's exergy efficiency. Such a modification of the electrolyzer's mode of operation is one of the improvements to be undertaken in future work on our test-bed system.

\section{Acknowledgement}

The authors are grateful to the Ministerio de Educación y Ciencia of Spain and the Junta de Extremadura for their financial support through the Projects ENE2007/66668/ALT, PRI07A088, and PDT07A047.

\section{References}

[1] Mahmoudi H, Abdul-Wahab SA, Goosen MFA, Sablani SS, Perret J, Ouagued A, Spahis N. "Weather data and analysis of hybrid photovoltaic-wind power generation systems adapted to a seawater greenhouse desalination unit designed for arid coastal countries”. Desalination 222 (2008) 119-127.

[2] Shakya BD, Aye L, Musgrave P. "Technical feasibility and financial analysis of hybrid wind-photovoltaic system with hyddrogen storage for Cooma". International Journal of Hydrogen Energy 30 (2005) 9-20.

[3] Calderón M, Calderón AJ, Ramiro A, González JF. Automatic management of energy flows of a stand-alone renewable energy supply with hydrogen support. International Journal of Hydrogen Energy 35 (2010) 2226-2235.

[4] Calderón M, Calderón AJ, Ramiro A, González JF. Weather data and energy balance of a hybrid photovoltaic-wind system with hydrogen storage. International Journal of Hydrogen Energy 35 (2010) 7706-7715.
[5] Dincer I, Rosen MA. Thermodynamics aspects of renewables and sustainable development. Renewable and Sustainable Energy Reviews 9 (2005) 169-189.

[6] Hepbasli A. A key on exergetic analysis and assessment of renewable energy resources for a sustainable future. Renewable and Sustainable Energy Reviews 12 (2008) 593-661.

[7] Dincer I, Rosen MA. Exergy analysis of renewable systems. Exergy (2007) 163-228.

[8] Nayak S, Tiwari GN. Energy and exergy analysis of photovoltaic/thermal integrated with a solar greenhouse. Energy and Buildings 40 (2008) 2015-2021.

[9] Joshi AS, Tiwari A. Energy and exergy efficiencies of a hybrid photovoltaic-thermal (PV/T) air collector. Renewable Energy 32 (2007) 2223-2241.

[10] Petela R. Exergy of undiluted thermal radiation. Solar Energy 74 (2003) 469-488.

[11] Candau Y. On the exergy of radiation. Solar Energy 75 (2003) 241-247.

[12] Chu SX, Liu LH. Analysis of terrestrial solar radiation exergy. Solar Energy 83 (2009) 1390-1404.

[13] Chow TT, Pei G, Fong KF, Lin Z, Chan ALS, Ji J. Energy and exergy analysis of photovoltaic-thermal collector with and whitout glass cover. Applied Energy 86 (2009) 310-316.

[14] Bejan A. Advanced Engineering Thermodynamics. John Wiley \& Sons, Inc. New York, 1997.

[15] Petela R. Exergy of heat radiation, Trans. ASME, J Heat Transfer 2 (1964) 187-192. 